\title{
Redes Corporais Sem Fio: Abordagens de MAC para Garantia de Eficiência e Confiabilidade na Comunicação sob Tráfego Dinâmico
}

\author{
Jorge F. Herculano*†, Willians de P. Pereira*‡, Marcelo A. Guimarães*§, Reinaldo M. Cotrim*ף Alirio S. de Sá*, \\ Flávio Assis*, Raimundo J. de A. Macêdo* e Sérgio Gorender* \\ *Laboratório de Sistemas Distribuídos (LaSiD), Programa de Pós-Graduação em Mecatrônica (PPGM), \\ Instituto de Matemática e Estatística, Universidade Federal da Bahia (UFBA) \\ ${ }^{\dagger}$ Universidade Federal do Sul da Bahia (UFSB) \\ ¥Instituto Federal de Educação, Ciência e Tecnologia de Rondônia (IFRO) \\ $\S$ Universidade Estadual do Sudoeste da Bahia (UESB) \\ IInstituto Federal de Educação, Ciência e Tecnologia Baiano (IFBaiano)
}

\begin{abstract}
Wireless Body Area Networks (WBANs) provide monitoring of physiological data without compromising patient mobility. In order not to affect patient health nor his/her mobility, nodes in a WBAN transmit data using short range and low power radio frequency electromagnetic waves. WBAN transmissions thus become subject to failures caused by interference or body mobility. Additionally, WBAN applications typically have timing constraints and dynamic traffic, which can change depending on the patient's physiological conditions. Several approaches to the Medium Access Control (MAC) sublayer have been proposed to WBANs in order to improve reliability and efficiency of these networks. In this paper, we propose and use a systematic review method to cover MAC approaches to WBAN efficiency and reliability under dynamic traffic, interference and body mobility.
\end{abstract}

Index Terms-WBAN, MAC, Healthcare, e-health

\section{INTRODUÇÃO}

Redes Corporais sem Fio (WBAN, Wireless Body Area Network) são compostas por dispositivos sensores e/ou atuadores, conectados ao corpo ou ao seu redor e com capacidade de coletar, processar informações e transmiti-las via radiofrequência [1]. Essas redes permitem desenvolver aplicações para apoiar os profissionais de saúde e aumentar a eficácia e confiabilidade nos cuidados à saúde dos pacientes, tais como [2]: monitoramento de atividades físicas e de doenças; deteç̧ão de emergências; acompanhamento de tratamento clínico etc.

WBANs devem atender a uma série de requisitos de aplicações para cuidados em saúde, por exemplo [3]: não comprometer a saúde, a mobilidade ou o conforto dos pacientes; oferecer confiabilidade e segurança na troca de dados entre os dispositivos etc. Esses requisitos implicam em vários desafios de projeto [4]: para aumentar a mobilidade e o conforto, os dispositivos possuem tamanho reduzido, implicando em restrições de autonomia de energia e no poder computacional; para limitar as emissões de radiofrequência (RF) absorvidas

Corresponding author: (jorge.herculano, willians.paula, marcelo.guimaraes, reinaldo.cotrim, aliriosa, fassis, macedo, gorender)@ufba.br. pelo corpo humano, as irradiações sem fio na WBAN precisam ser de baixa potência e curto alcance, podendo sofrer interferências do ambiente e da mudança na postura do paciente [5]; dispositivos específicos tratam diferentes parâmetros fisiológicos, portanto, são heterogêneos, com diferentes taxas de transmissão e tipos de tráfego, desde regulares e periódicos até tráfegos de emergência. Tráfegos dinâmicos, em particular, principalmente em situações de emergência, aumentam o desafio, pois os parâmetros fisiológicos do paciente estão correlacionados, podendo implicar na transmissão concorrente de dados a partir de dispositivos distintos [5]-[7].

Nesse cenário, organizar as transmissões sem fio entre os dispositivos da WBAN não é trivial. Isso porque, além dos requisitos das aplicações médicas e das características inerentes à WBAN, o controle de acesso ao meio de comunicação sem fio também deve considerar fenômenos físicos que comprometem a confiabilidade da transmissão [2]. Assim, vários protocolos de Controle de Acesso ao Meio (MAC, Medium Access Control) têm sido propostos para disciplinar a comunicação sem fio e garantir desempenho, confiabilidade e eficiência para aplicações baseadas em WBANs [6], [8].

Este artigo apresenta três contribuições principais. Primeiro, propõe um método de Revisão Sistemática da Literatura (RSL) que seleciona publicações não apenas por critérios quantitativos, em termos do número de citações, mas também por critérios qualitativos relacionados a aspectos metodológicos e estruturais das publicações. Além disso, usa análises de agrupamentos (clustering) com base nos critérios de qualidade e de relevância adotados. Segundo, utiliza o método de RSL proposto para investigar e analisar como as abordagens existentes para a subcamada MAC das WBANs lidam com falhas de comunicação, acomodam tráfego dinâmico e como influenciam a confiabilidade e a eficiência da rede. Terceiro, a partir da análise dos trabalhos selecionados, mapeia as abordagens e oportunidades de pesquisa.

A seguir, são apresentados: o método de elaboração e os resultados desta RSL (seções II e III); os trabalhos relacionados (Seção IV); e as conclusões deste trabalho (Seção V). 


\section{Método da Revisão Sistemática da Literatura}

O método proposto nesta RSL, baseado em [9]-[11], é descrito nas Subseções II-A e II-B As inovações desta RSL são descritas na Subseção II-B

\section{A. Questões de Pesquisa e Estratégia de Busca}

Esta RSL objetiva responder a seguinte questão de pesquisa: "Quais abordagens propostas para a subcamada MAC das WBANs garantem qualidade, eficiência e confiabilidade na aquisição de dados sob diferentes condições de tráfego?”.

Para obter um melhor panorama das abordagens, foram estabelecidas questões secundárias: QS1 - quais estratégias são adotadas para melhorar confiabilidade? QS2 - quais estratégias são adotadas para melhorar a eficiência do tráfego de mensagens (taxa de entrega e latência da transmissão)? QS3 - quais estratégias são adotadas para melhorar a eficiência energética? QS4 - quais estratégias são adotadas para acomodar o tráfego dinâmico? QS5 - quais estratégias são adotadas para acomodar o tráfego de emergência?

Os termos para as buscas na literatura foram definidos a partir das questões de pesquisa. Além dos termos WBAN, MAC e seus sinônimos, foram incluídos os termos mobilidade, interferência, colisão, path loss (perda de caminho), fading (desvanecimento de sinal) e deep fading (desvanecimento profundo), por serem os principais aspectos que comprometem a confiabilidade, a eficiência energética e o tráfego da rede [3]. A busca considerou publicações em inglês e em português. Para buscas por publicações em língua inglesa, utilizou-se a expressão: (wban OR "wireless body area network" OR wbans OR "wireless body area networks") AND (mobility OR interference OR collision OR "path loss" OR "deep fade" OR fading) AND (mac OR "medium access control”). Para buscas por publicações em português, traduziram-se alguns termos, resultando na expressão: (wban OR "wireless body area network" OR wbans OR "wireless body area networks”) AND (mobilidade OR interferência OR colisão OR "perda de caminho" OR "desvanecimento profundo" OR "desvanecimento”) AND (mac OR “controle de acesso ao meio”).

A busca por publicações em inglês foi realizada em todos os repositórios da Tabela I] enquanto que a busca por publicações em português foi realizada apenas no Google Scholar. A escolha dos repositórios se deu pela relevância na comunidade científica. Foram consideradas todas as publicações existentes nessas bases até janeiro de 2021. Os resultados das buscas foram salvos em arquivos bibtex e importados para a ferramenta de gerenciamento de referências Mendeley 1 , onde foram aplicados os filtros 1 a 4, selecionando 286 dos 9.396 trabalhos encontrados (ver Tabela I).

O Filtro 1 removeu duplicidades e livros e capítulos de livros sem livre acesso ou não acessíveis através do Portal de Periódicos CAPES ${ }^{2}$ Na coleta inicial, não se restringiram os campos de dados das publicações em que as expressões de busca foram aplicadas, retornando publicações fora do

\footnotetext{
${ }^{1}$ https://www.mendeley.com/

${ }^{2}$ https://periodicos.capes.gov.br/
}

Tabela I

REPOSITÓRIOS PESQUISADOS

\begin{tabular}{|l|l|l|l|l|l|l|}
\hline Repositório (URL) & $\begin{array}{l}\text { Coleta } \\
\text { Inicial }\end{array}$ & F1 & F2 & F3 & Junção & F4 \\
\hline dl.acm.org & 536 & 282 & 63 & 28 & & \\
ieeexplore.ieee.org & 110 & 106 & 101 & 76 & & \\
digital-library.theiet.org & 87 & 74 & 5 & 4 & & \\
pubmed.ncbi.nlm.nih.gov & 23 & 0 & 0 & 0 & & \\
scholar.google.com.br & 7109 & 5547 & 619 & 246 & 458 & 286 \\
www.sciencedirect.com & 661 & 252 & 32 & 14 & & \\
link.springer.com & 602 & 532 & 87 & 42 & & \\
www.webofknowledge.com & 161 & 84 & 74 & 45 & & \\
onlinelibrary.wiley.com & 107 & 63 & 13 & 3 & & \\
\hline
\end{tabular}

escopo desta RSL, apenas por citar alguns termos de busca no texto. Para se limitar ao escopo desta RSL, o Filtro 2 removeu publicações sem os termos (wban OR "Wireless body area network" OR wbans OR "Wireless body area networks") AND (mac OR "medium access control") no título e/ou resumo/abstract. O Filtro 3 removeu publicações com menos de 5 páginas e artigos de revisão sem novas abordagens para a subcamada MAC. Por fim, o Filtro 4 excluiu trabalhos que não tratavam diretamente da subcamada MAC e/ou faziam apenas análises comparativas de abordagens de outros autores.

\section{B. Avaliação da Qualidade e Relevância das Publicações}

A avaliação da qualidade das publicações consiste em identificar os trabalhos que apresentam aspectos metodológicos e estruturais que atendam aos seguintes critérios de qualidade: (i) Declaram de forma clara os objetivos da pesquisa [11]? (ii) Posicionam as propostas em relação ao estado da arte? (iii) Propõem soluções viáveis (para um cenário real) [11]? (iv) As simulações ou experimentos são completamente analisados e explicados, e os resultados dos testes apoiam fortemente as ideias apresentadas no trabalho [11]? (iv) Comparam suas soluções com outras existentes?

A avaliação da relevância consiste em identificar aspectos dos trabalhos que respondam às questões de pesquisa desta RSL. Para tanto, foram adotados os seguintes critérios: (i) Apresentam estratégia para melhorar confiabilidade? (ii) Apresentam estratégia para melhorar a eficiência do tráfego de mensagens (taxa de entrega e latência)? (iii) Apresentam estratégia para melhorar a eficiência energética? (iv) Apresentam estratégia para acomodar o tráfego dinâmico? (v) Apresentam estratégia para lidar com tráfego de emergência?

Para responder às questões de avaliação dos critérios de qualidade e relevância, foi utilizada a seguinte escala de valores: zero, se não atende ao critério; 0,5 (meio), se atende parcialmente ao critério; e 1,0 (um), se atende ao critério.

As 286 publicações selecionadas foram analisadas e pontuadas usando os critérios de qualidade e relevância descritos. Os dados extraídos das publicações foram organizados em uma planilha e importados para o software $\mathrm{R}^{3}$ para processamento e geração de gráficos. Em seguida, aplicou-se o método $k$ means [12] para agrupar publicações semelhantes em termos de qualidade e relevância. No k-means, é especificado o

${ }^{3}$ https://www.r-project.org/ 
número de agrupamentos (clusters) desejados e cada objeto é atribuído a um agrupamento com base nos seus valores, obedecendo a uma medida de distância. Neste trabalho, foram realizados agrupamentos usando a distância Euclidiana entre as pontuações de qualidade e relevância das publicações.

Com base nas pontuações de qualidade, distribuíram-se as 286 publicações em três grupos (ver Figura 1): qualidade Muito Significativa, com 154 publicações; qualidade Significativa, com 55 publicações; e qualidade Pouco Significativa, com 77 publicações. Em relação às pontuações de relevância, também se distribuíram as 286 publicações em três grupos (ver Figura 1): relevância Muito Significativa, com 129 publicações; relevância Significativa, com 90 publicações; e relevância Pouco Significativa, com 67 publicações. Dentre as 286 publicações, 78 pertenciam simultaneamente aos agrupamentos de qualidade e de relevância Muito Significativa.

Além dos critérios de qualidade e relevância acima, observou-se também o número de citações das 286 publicações no Google Scholar. Então, de acordo com o número de citações, organizaram-se as 286 publicações em três categorias (ver Figura 11): na categoria Pouco Significativa, foram incluídas 168 publicações com até 9 citações cada; na categoria Significativa, foram incluídas 53 publicações contendo entre 10 e 19 citações cada; e, na categoria Muito Significativa, foram incluídas 65 publicações com mais de 19 citações cada.

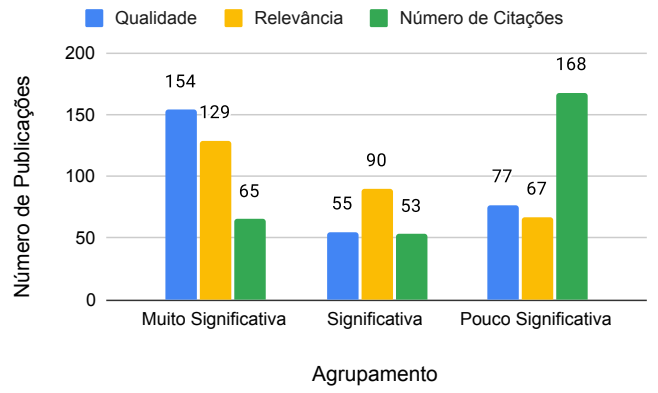

Figura 1. Agrupamentos baseados nos critérios de qualidade e relevância

Dentre as 65 publicações da categoria de citações Muito Significativa, 43 não atendem completamente aos critérios de qualidade e relevância Muito Significativas. Todavia, devido à importância que essas publicações têm para a comunidade científica, elas foram incluídas nesta RSL, totalizando 121 publicações escolhidas para responder às questões de pesquisa: 78 pelos critérios de qualidade e relevância; e 43 apenas pelo número de citações. A lista das 121 publicações escolhidas e um resumo dos dados extraídos das mesmas estão disponíveis em https://bityli.com/apendice-rsl-mac

\section{RESUlTADOS DA RSL}

Os trabalhos que melhor atendem aos critérios desta RSL se concentraram após 2006 (ver Figura 2), quando surgiram novos dispositivos inteligentes para WBANs [13], [14].

A partir das 121 publicações selecionadas, foram identificados diversos desafios relacionados à subcamada MAC das

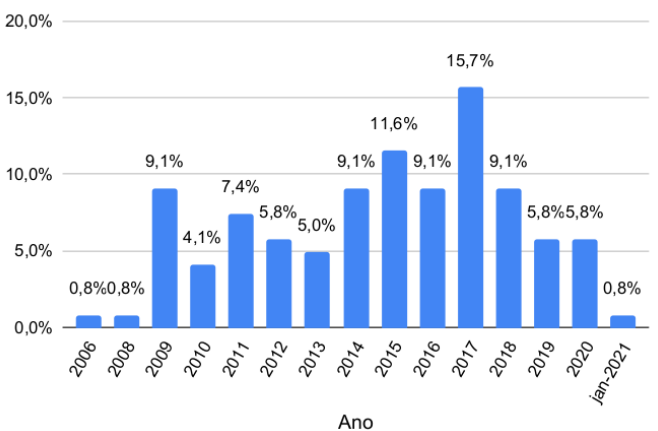

Figura 2. Percentual das Publicações por ano, até janeiro de 2021

WBANs. A Tabela III associa os desafios identificados às questões de pesquisa nas quais os mesmos impactam e aos percentuais dos trabalhos que lidam com cada desafio. Como os trabalhos abordam mais de um desafio, os percentuais da Tabela I] somam mais de $100 \%$. Dentre os desafios identificados, destacam-se: acomodação dos tráfegos dinâmico e de emergência; consumo de energia; latência; e colisão.

Tabela II

RELAÇÃO ENTRE OS DESAFIOS ABORDADOS E AS QUESTÕES DE PESQUISA

\begin{tabular}{|l|c|l|}
\hline Desafios & \% de Publicações & Questões de Pesquisa \\
\hline Elevação de Temperatura & 0,8 & QS3 \\
Estouro de Buffer & 0,8 & QS1 \\
Sobrecarga & 2,5 & QS2 \\
Path Loss & 3,3 & QS1 e QS2 \\
Fading & 5 & QS1, QS2 e QS3 \\
Interferência & 14 & QS1, QS2 e QS3 \\
Colisão & 37,9 & QS1, QS2 e QS3 \\
Latência & 41,3 & QS2 e QS5 \\
Tráfego de Emergência & 49,6 & QS5 \\
Consumo de Energia & 50,4 & QS3 \\
Tráfego Dinâmico & 50,4 & QS4 \\
\hline
\end{tabular}

A interferência, abordada em $14 \%$ das publicações, ocorre devido à competição entre dispositivos de redes distintas pelo uso de um mesmo canal de comunicação sem fio, ou por ruídos que geram perda e corrupção dos dados transmitidos.

A atenuação do sinal de transmissão (Fading) e a desconexão (Path Loss) entre os dispositivos da rede, pouco tratadas nos trabalhos, respectivamente $5 \%$ e $3,3 \%$ das publicações, impactam diretamente na confiabilidade e eficiência da WBAN e são consequências da mudança de postura do paciente, de outros obstáculos do ambiente e de condições climáticas.

A sobrecarga de dados de controle na rede, apesar de aumentar as colisões, gerando atrasos e corrupção dos dados, foi tratada apenas em 2,5\% dos trabalhos. Também não foram tratados adequadamente a elevação de temperatura dos dispositivos e o estouro de buffer, observados em menos de $1 \%$ dos trabalhos cada um. A elevação de temperatura dos dispositivos pode danificar o tecido do paciente e é causada por parte da energia consumida pelo dispositivo que é dissipada em forma de calor, principalmente durante as transmissões. $\mathrm{O}$ estouro de buffer, provocado pela limitação de armazenamento dos dispositivos, causa perda de dados, principalmente em mecanismos para tolerar falhas de comunicação. 
Para lidar com esses desafios, os protocolos MAC podem combinar duas ou mais abordagens, tais como: priorização de tráfego, mecanismos de sincronização, tipos de transceptores e políticas de acesso ao meio. A Tabela III associa as questões de pesquisa às abordagens adotadas e os percentuais dos trabalhos que respondem a tais questões.

Tabela III

ABORDAGENS ADOTADAS PARA AS QUESTÕES DE PESQUISA

\begin{tabular}{|c|l|c|}
\hline $\begin{array}{l}\text { Questão de } \\
\text { Pesquisa }\end{array}$ & \multicolumn{1}{|c|}{ Abordagens Adotadas } & $\begin{array}{l}\text { \% de } \\
\text { Publicaçóes }\end{array}$ \\
\hline QS1 & $\begin{array}{l}\text { Mecanismos de Sincronização, Tipos de Transcep- } \\
\text { tores e Políticas de Acesso ao Meio. }\end{array}$ & 62,8 \\
\hline QS2 & $\begin{array}{l}\text { Mecanismos de Sincronização, Tipos de Transcep- } \\
\text { tores, Priorização de Tráfego e Políticas de Acesso } \\
\text { ao Meio. }\end{array}$ & 58,7 \\
\hline QS3 & $\begin{array}{l}\text { Mecanismos de Sincronização, Priorização de } \\
\text { Tráfego, Tipos de Transceptores e Políticas de } \\
\text { Acesso ao Meio. }\end{array}$ & 69,4 \\
\hline QS4 & $\begin{array}{l}\text { Priorização de Tráfego, Tipos de Transceptores e } \\
\text { Políticas de Acesso ao Meio. }\end{array}$ & 49,6 \\
\hline QS5 & $\begin{array}{l}\text { Priorização de Tráfego, Tipos de Transceptores e } \\
\text { Políticas de Acesso ao Meio. }\end{array}$ & 49,6 \\
\hline
\end{tabular}

Um mapeamento mais detalhado de cada uma das abordagens identificadas é apresentado nas subseções a seguir. Como poderá ser observado mais adiante, muitas soluções se baseiam nas especificações IEEE 802.15.4 [15] e IEEE 802.15.6 [16]. Apesar de existirem outras especificações, como a SmartBAN [17], as especificações 802.15.4 e 802.15.6 são vistas pela comunidade científica como referência para WBANs.

\section{A. Priorização de Tráfego}

Os diferentes tipos de tráfego e de dispositivos aumentam a complexidade do controle de acesso ao meio, resultando em maior latência e dificuldade de acomodação dos tráfegos dinâmico e de emergência. A principal estratégia adotada para lidar com esses desafios é a classificação e priorização dos tráfegos, obtendo baixa latência nas transmissões, maior confiabilidade e eficiência energética - o que se relaciona às questões de pesquisa QS2, QS3, QS4 e QS5 desta RSL.

Dentre as publicações selecionadas, 32,2\% utilizam duas categorias de tráfego: normal; e crítico ou de emergência. A maioria das publicações $(49,6 \%)$ considera mais de duas categorias, enquanto que $18,2 \%$ das publicações não especificaram quaisquer categorias de prioridades.

\section{B. Tipos de Transceptores}

Cada dispositivo da WBAN possui ao menos um transceptor de RF junto com seu mecanismo de controle de camadas física e MAC [15]. A adição de transceptores ou uso de algum transceptor específico impacta no modo como a subcamada MAC lida com colisões (QS1 e QS2), consumo de energia (QS3) e tráfegos dinâmico (QS4) e de emergência (QS5).

A maioria das abordagens, 89,3\% dos trabalhos, usa um transceptor baseado na IEEE 802.15.4 ou na IEEE 802.15.6 Em 7,4\% das abordagens utiliza-se wake-up radio, um transceptor secundário, acoplado ao dispositivo e controlado por um circuito despertador, operando com baixo consumo de energia. Ao receber um sinal de controle do wake-up radio, o dispositivo poderá realizar alguma ação, como ligar o rádio principal para transmissão dos dados, economizando energia e melhorando o tempo de resposta, principalmente para o tráfego de emergência. Wake-up radios não são usados em dispositivos implantados e em situações com muita limitação de espaço físico, o que restringe o uso desses transceptores.

Em 2,5\% das abordagens, são usados transceptores com antenas direcionais. Essas antenas distribuem feixes, a partir de uma base fixa, ampliando a área de atuação e permitindo transmissões simultâneas e sem colisões. Contudo, o uso dessas antenas não prevê a mobilidade do paciente, tendo desempenho comprometido quando mudanças na postura do paciente mudam a posição dos dispositivos.

\section{Políticas de Acesso ao Meio}

A confiabilidade e a eficiência dos protocolos variam de acordo com as políticas adotadas para acesso ao meio sem fio. Essas políticas podem ser categorizadas em: baseadas em contenção, livres de contenção e híbridas.

Políticas baseadas em contenção estão em 18,2\% dos trabalhos, adotam o CSMA-CA [18] e acomodam melhor os tráfegos dinâmico (QS4) e de emergência (QS5), mas são susceptíveis a colisões e retransmissões, sendo mais adequadas em aplicações sem muitas restrições de energia e de confiabilidade. Podem ser divididas em três grupos: o primeiro propõe melhorias no período de contenção do 802.15 .4 e abrange $36,4 \%$ das abordagens; o segundo propõe melhorias nos períodos de contenção do 802.15 .6 e abrange $45,5 \%$ das abordagens; o terceiro não se baseia na especificação IEEE e abrange $18,2 \%$ das abordagens.

Nos protocolos MAC que utilizam políticas livres de contenção, os dispositivos são escalonados obedecendo uma ordem preestabelecida para transmissão dos dados. Nesse caso, não há competição pelo canal e cada dispositivo recebe slots de tempo ou faixas de frequência (i.e., múltiplos canais) para transmissão. Dessa forma, economizam energia, já que evitam colisões e reduzem as retransmissões (QS1 e QS3). As técnicas mais usadas são TDMA, FDMA e Polling [18]. Esses protocolos estão em $25,6 \%$ das publicações selecionadas, sendo: $41,9 \%$ baseados no $802.15 .4 ; 16,1 \%$ baseados no 802.15 .6 ; e $41,9 \%$ não se baseiam nas especificações IEEE.

A maioria dos protocolos, 56,2\% do total, adota políticas híbridas, combinando flexibilidade na acomodação do tráfego, fornecida pelas políticas baseadas em contenção, com mecanismos de controle de energia das políticas livres de contenção. Todavia, políticas híbridas podem ocasionar maior sobrecarga de dados de controle na rede. Dentre os protocolos, 44,1\% se baseiam na especificação $802.15 .4,42,6 \%$ se baseiam no 802.15.6 e 13,2\% não se baseiam nas especificações IEEE.

Políticas baseadas em contenção melhoram a confiabilidade (QS1) e acomodam bem os tráfegos dinâmico (QS4) e de emergência (QS5). Contudo, políticas livres de contenção melhoram a eficiência energética (QS3) e o tráfego dos dados (QS2). Por fim, políticas híbridas lidam bem com tráfegos dinâmico e de emergência e têm boa eficiência energética. 


\section{Mecanismos de Sincronização}

Interferência, colisão e sobrecarga de dados impactam na confiabilidade (QS1), eficiência (QS2) e consumo de energia (QS3) da WBAN. Para lidar com esses desafios, mecanismos de sincronização têm sido adotados, permitindo que os dispositivos sincronizem a comunicação e evitem colisões e interferências. Muitas soluções, baseadas nas especificações IEEE 802.15.4 e 802.15.6, consideram a existência de um dispositivo coordenador de rede e usam dois modos de sincronização: habilitado por beacon e habilitado sem beacon. Um beacon é uma mensagem de controle com informações de gerenciamento e de sincronização entre os dispositivos [16].

O modo habilitado por beacon pode ser periódico ou sob demanda. $\mathrm{O}$ modo periódico utiliza um beacon no início de cada superquadro. $\mathrm{O}$ superquadro consiste em um intervalo de tempo delimitado por beacons, enviados periodicamente pelo coordenador da rede para definir o formato do superquadro e manter os dispositivos sincronizados. Um superquadro pode ser dividido, opcionalmente, em duas partes: uma parte ativa e outra inativa. Na parte inativa, os nós entram em modo de baixo consumo de energia para prolongar a vida da rede [15]. Algumas abordagens utilizam beacons adicionais e pequenas mensagens de notificação (e.g., ACK). Essas mensagens são enviadas durante o superquadro para adaptar o uso dos recursos à variação do tráfego e reduzir o consumo de energia. Esse modo foi utilizado em $86,8 \%$ das publicações. No modo sob demanda, usado em $4,1 \%$ das publicações, o beacon é enviado pelo coordenador quando percebe alterações de prioridade na rede ou quando detecta mudança no relógio dos dispositivos.

O modo habilitado sem beacon é utilizado em 3,3\% das publicações, principalmente nas abordagens baseadas em contenção. Nesse modo, os dispositivos sincronizam usando pequenas mensagens (e.g., ACK) com os valores dos relógios.

Em 5,8\% das publicações, combinam-se políticas baseadas em contenção com preâmbulo, um quadro comumente usado para permitir que o receptor se prepare para receber uma mensagem e sincronizar seu relógio com o do remetente [18].

As publicações indicam que beacons periódicos são mais adequados quando usados com políticas livres de contenção ou políticas híbridas, pois é necessário constante sincronização entre os dispositivos para a reserva dos slots de tempo. O modo sem beacons, beacons sob demanda ou preâmbulos são mais usados com as políticas baseadas em contenção.

\section{TRabalhos Relacionados}

Uma revisão de literatura sobre características, problemas e desafios em WBANs para aplicações médicas é apresentada em [14], avaliando as principais tecnologias envolvidas nessas redes, como os sensores vestíveis e implantáveis, e apontando tendências na literatura, entre o período de 2008 a 2018. Em [19], são examinadas as tecnologias e aplicações mais recentes da WBAN em telemedicina, concentrando-se nos aplicativos relacionados à triagem de pacientes, sem focar em MAC. Em [13], são descritos conceitos, aplicações, desafios e abordagens para o roteamento de mensagens em WBANs.
Em [20], é apresentada uma revisão das principais técnicas usadas na implementação das WBANs, além das características que as diferem das outras redes de sensores sem fio. Discutem-se também estudos relacionados às camadas MAC, física e de aplicação, enfatizando as principais tendências da literatura entre o período de 2003 a 2014. Em [21], é apresentada uma visão geral das WBANs, incluindo diversos dispositivos que podem ser usados na rede. Além disso, os requisitos de comunicação, qualidade de serviço e segurança também são apontados. Em [6], abordam-se os requisitos de implementação de WBANs com base no padrão IEEE 802.15.6, apresentando aspectos conceituais, estrutura geral de comunicação, classificação e aplicações. Contudo, concentrase em redes definidas por software e coleta de energia.

Em [22], apresenta-se uma revisão dos principais protocolos MAC para atender ao tráfego de emergência. Essa revisão cobre apenas os trabalhos realizados até dezembro de 2016 e não aborda os problemas e estratégias referentes às questões de comunicação. Em [8], também é apresentada uma revisão sobre protocolos MAC publicados até 2016, mas não se abordam as questões associadas a diferentes tipos de tráfego.

Em [3], são explorados conceitos e tecnologias para implantação de uma WBAN, incluindo aspectos de tolerância a falhas para a subcamada MAC. Em [23], são apresentados protocolos MAC com foco em eficiência energética. Contudo, tanto em [3] quanto em [23], os tráfegos dinâmico e de emergência não são discutidos. Em [2], são discutidos os principais avanços tecnológicos das WBAN até 2013. Em [5], apresenta-se uma revisão das soluções para as camadas física, MAC e de rede, mas apenas com trabalhos até 2010.

Até o momento, em relação aos desafios específicos da subcamada MAC das WBANs, os trabalhos relacionados trazem inúmeras informações sobre aplicações, características e desafios, mas não abordam o tema de forma sistematizada. As três revisões sistemáticas existentes utilizam apenas critérios quantitativos para seleção das publicações. Os demais trabalhos são revisões narrativas. Esta RSL mapeia de forma mais específica as soluções propostas para a subcamada MAC, concentrando-se nas garantias de qualidade e eficiência sob diferentes condições de tráfego e mobilidade do paciente. Além disso, utiliza critérios qualitativos, que avaliam a qualidade e relevância dos trabalhos, e critérios quantitativos, em termos do número de citações das publicações.

\section{Discussões E CONSIDERAÇÕES FINAIS}

Este artigo mapeou e analisou as abordagens adotadas na subcamada MAC das WBANs para garantir qualidade e eficiência na aquisição de dados em diferentes condições de tráfego e permitir a mobilidade do paciente. Para tanto, apresentou um método de RSL que considera, na seleção das publicações, não apenas o número de citações, mas também o rigor metodológico dos trabalhos e a relevância desses trabalhos para as questões de pesquisa propostas.

As abordagens adotadas nos trabalhos estão relacionadas com priorização de tráfegos, mecanismos de sincronização, tipos de transceptores utilizados e políticas de acesso ao meio. 
Priorização de tráfegos é essencial para lidar com tráfegos dinâmico (QS4) e de emergência (QS5). As publicações apontam que usar dois níveis de prioridade pode aumentar a eficiência no suporte aos tráfegos dinâmico e de emergência e reduzir a complexidade na alocação do canal de comunicação.

Mecanismos de sincronização são importantes para que os dispositivos evitem colisões e interferências, principalmente combinados com políticas livres de contenção, aumentando a confiabilidade (QS1) e melhorando o tráfego de mensagens (QS2). No entanto, o uso de mensagens de controle em excesso para manter a sincronização, principalmente sob tráfego dinâmico, aumenta a sobrecarga de dados na rede, impactando a eficiência energética (QS3). Outra abordagem para melhorar a sincronia entre os dispositivos é a adição de mais transceptores, como rádios wake-up. Essa abordagem melhora a eficiência energética (QS3), principalmente sob tráfego de emergência, mas aumenta a complexidade dos dispositivos e ainda não é viável quando há limitações de espaço físico ou em dispositivos implantados.

Com relação às políticas de acesso ao meio, as estratégias baseadas em contenção acomodam melhor os tráfegos dinâmico (QS4) e de emergência (QS5), pois os dispositivos podem realizar tentativas de acesso ao canal a qualquer momento. Contudo, nas diferentes propostas, colisões podem implicar em retransmissões e aumentar o consumo de energia (QS3), além de reduzir a confiabilidade da rede (QS1).

Nas políticas livres de contenção não há colisões, logo reduzem o atraso na entrega das mensagens (QS2) e aumentam a eficiência energética (QS3) e a confiabilidade (QS1). A presença de tráfego dinâmico exige rearranjo dos slots de transmissão dos dispositivos, podendo prejudicar a acomodação dos tráfegos e atrasar a entrega das mensagens. Algumas estratégias reservam slots de transmissão para o tráfego de emergência, desperdiçando banda, pois situações de emergência não ocorrem com frequência.

As políticas com abordagens híbridas de acesso ao meio combinam as facilidades das abordagens baseadas em contenção, em termos de alocação de tráfegos dinâmico (QS4) e de emergência (QS5), com a confiabilidade (QS1) presente em abordagens livres de contenção. Todavia, ainda é um desafio determinar como chavear entre as abordagens para obter melhor desempenho, confiabilidade e eficiência.

Por fim, a maioria dos trabalhos lidou com problemas de consumo de energia, latência e colisão. Problemas como desvanecimento, sobrecarga, desconexão e efeitos térmicos são pouco explorados e ainda demandam esforços para que as WBANs suportem a mobilidade do paciente e sejam referência nas aplicações em saúde. Além disso, apesar de muitas abordagens buscarem lidar com tráfegos dinâmico e de emergência, esses ainda não são tratados de forma adequada nos trabalhos.

\section{REFERÊNCIAS}

[1] R. Cavallari, F. Martelli, R. Rosini, C. Buratti, and R. Verdone, "A survey on wireless body area networks: Technologies and design challenges," IEEE Communications Surveys and Tutorials, vol. 16, no. 3, pp. $1635-1657,2014$
[2] S. Movassaghi, M. Abolhasan, J. Lipman, D. Smith, and A. Jamalipour, "Wireless body area networks: A survey," IEEE Communications Surveys and Tutorials, vol. 16, no. 3, pp. 1658-1686, 2014.

[3] M. Salayma, A. Al-Dubai, I. Romdhani, and Y. Nasser, "Wireless Body Area Network (WBAN): A survey on reliability, fault tolerance, and technologies coexistence," ACM Computing Surveys, vol. 50, no. 1, pp. $1-38,2017$.

[4] B. Latré, B. Braem, I. Moerman, C. Blondia, and P. Demeester, "A survey on wireless body area networks," Wireless Networks, vol. 17, no. 1, pp. 1-18, 2011.

[5] S. Ullah, H. Higgins, B. Braem, B. Latre, C. Blondia, I. Moerman, S. Saleem, Z. Rahman, and K. S. Kwak, "A comprehensive survey of wireless body area networks on PHY, MAC, and network layers solutions," J. of Medical Systems, vol. 36, no. 3, pp. 1065-1094, 2012.

[6] K. Hasan, K. Biswas, K. Ahmed, N. S. Nafi, and M. S. Islam, "A comprehensive review of wireless body area network," Journal of Network and Computer Applications, vol. 143, pp. 178-198, 2019.

[7] S. Ullah, B. Shen, S. M. Riazul Islam, P. Khan, S. Saleem, and K. S. Kwak, "A study of MAC protocols for WBANs," Sensors, vol. 10, no. 1, pp. $128-145,2010$

[8] F. Ullah, A. H. Abdullah, O. Kaiwartya, S. Kumar, and M. M. Arshad, "Medium Access Control (MAC) for Wireless Body Area Network (WBAN): Superframe structure, multiple access technique, taxonomy, and challenges," Human-centric Computing and Information Sciences, vol. 7 , no. $1,2017$.

[9] L. C. Gubert, C. A. da Costa, and R. d. R. Righi, "Context awareness in healthcare: a systematic literature review," Universal Access in the Information Society, jul 2019. [Online]. Available: http://link.springer.com/10.1007/s10209-019-00664-z

[10] B. Kitchenham, O. Pearl Brereton, D. Budgen, M. Turner, J. Bailey, and S. Linkman, "Systematic literature reviews in software engineering - A systematic literature review," Information and Software Technology, vol. 51, no. 1, pp. 7-15, 2009.

[11] C. M. De Farias, W. Li, F. C. Delicato, L. Pirmez, A. Y. Zomaya, P. F. Pires, and J. N. De Souza, "A Systematic Review of Shared Sensor Networks," ACM Computing Surveys, vol. 48, no. 4, pp. 1-50, 2016.

[12] Pang-Ning Tan, M. Steinbach, A. Karpatne, and V. Kumar, Introduction to Data Mining, 2nd ed. Pearson, 2019.

[13] B. Abidi, A. Jilbab, and E. H. Mohamed, "Wireless body area networks: a comprehensive survey," J. of Medical Engineering and Technology, pp. $1-11,2020$.

[14] S. Shokeen and D. Parkash, "A Systematic Review of Wireless Body Area Network," in 2019 International Conference on Automation, Computational and Technology Management. IEEE, apr 2019, pp. 58-62.

[15] IEEE, "IEEE Standard for Low-Rate Wireless Networks," IEEE, Tech. Rep., 2016.

[16] 15.6: Wireless Body Area Networks," IEEE, Tech. Rep. February, 2012.

[17] ETSI, "Low Complexity Medium Access Control (MAC) for SmartBAN," ETSI, Tech. Rep., 2015.

[18] A. S. Tanenbaum and D. Wetherall, Computer Networks, 5th ed. Boston: Prentice Hall, 2011.

[19] O. S. Albahri, A. S. Albahri, K. I. Mohammed, A. A. Zaidan, B. B. Zaidan, M. Hashim, and O. H. Salman, "Systematic Review of Realtime Remote Health Monitoring System in Triage and Priority-Based Sensor Technology: Taxonomy, Open Challenges, Motivation and Recommendations," J. of Medical Systems, vol. 42, no. 5, p. 80, may 2018.

[20] I. Ha, "Technologies and research trends in wireless body area networks for healthcare: A systematic literature review," International Journal of Distributed Sensor Networks, vol. 2015, 2015.

[21] V. Ferreira, E. Caballero, R. Lima, H. Balbi, F. Seixas, C. Albuquerque, and D. Muchaluat-Saade, "Redes Corporais Sem Fio e Suas Aplicações em Saúde," in Jornadas de Atualização em Informática, 2018, pp. 149198.

[22] F. Masud, A. H. Abdullah, G. Abdul-Salaam, and M. K. Ishfaq, "Emergency traffic MAC protocols in wireless body area networks," Ad-Hoc and Sensor Wireless Networks, vol. 41, no. 1-2, pp. 83-113, 2018.

[23] R. Sruthi, "Medium Access Control Protocols for Wireless Body Area Networks: A Survey," Procedia Technology, vol. 25, no. Raerest, pp. 621-628, 2016 